Tendencias

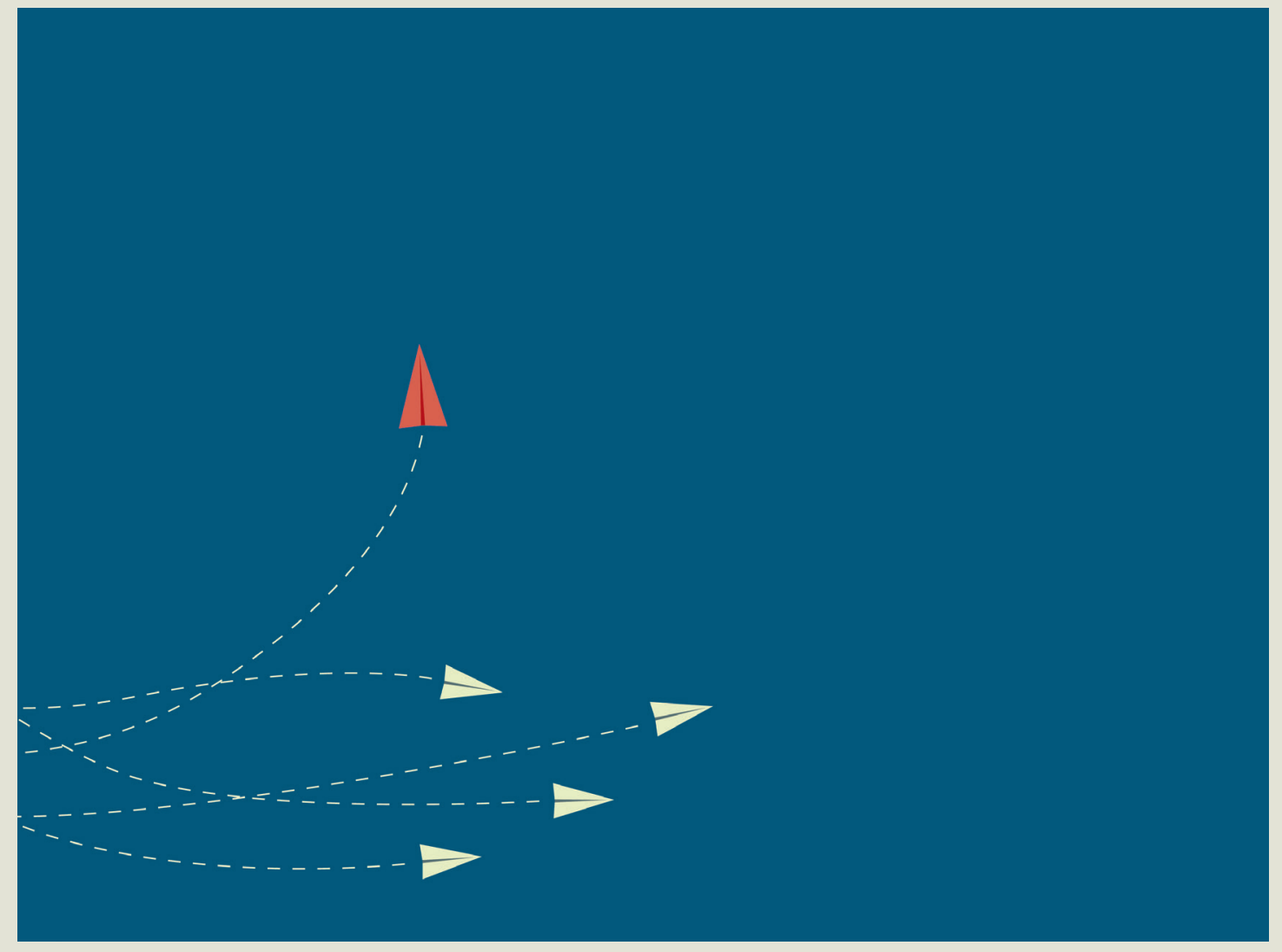





\title{
El cuerpo como capital social en Instagram: el caso de @adri_vainilla
}

\author{
Omar Vite \\ Pontificia Universidad Católica del Perú \\ vite.vo@gmail.com
}

Recibido: 4/9/2017 / Aceptado: 6/11/2017

doi: 10.26439/contratexto2018.n029.1553

\begin{abstract}
Resumen. Según José Van Dijck (2016), los sitios de redes sociales se han convertido en un espacio fundamental para la acumulación de capital social. Para entender cómo se construye el capital social en las redes sociales, analizaremos el caso de Adri Vainilla. Examinaremos el contenido publicado en las plataformas de redes sociales donde ella tiene presencia. En particular, en esta investigación nos centraremos en las publicaciones realizadas entre el 23 de agosto y el 23 de septiembre del 2016 en su perfil de Instagram. El estudio nos permite concluir que el capital social es el resultado de la interacción entre la mirada del observador y la imagen que emana del individuo o actuante.
\end{abstract}

Palabras clave: redes sociales / capital social / selfie / cuerpo / mujer 


\title{
The Body as Social Capital on Instagram: A Case Study on @adri_vainilla
}

\begin{abstract}
According to José Van Dijck (2016), social networking sites have become a fundamental space for the accumulation of social capital. Taking the case of Adri Vainilla as an example, this study aims to explain how social capital is constructed in social networks. To achieve this, we will analyze the content published in social networks' platforms in which she has presence. In particular, this research will focus on posts made between August 23 and September 23, 2016 on her Instagram profile. This study allows us to conclude that social capital is a result of the interaction between the observer's gaze and the image that emanates from the individual or the actant.
\end{abstract}

Keywords: social networks / social capital / selfie / body / woman 


\section{Introducción}

$\mathrm{E}$

115 de marzo del 2000 la editorial alemana Taschen publicó Digital

Diaries, el primer libro impreso de fotografía digital, con 250 páginas. Fue considerado en su momento "una audaz exploración erótica en los albores de la era digital" (Merritt, 2015). Apareció dieciocho meses antes del 11 de septiembre del 2001, el día en que según la economista italiana Loretta Napoleoni (2012) comenzó una década que ha cambiado profundamente el mundo (p. 9).

La autora de Digital Diaries es la artista, escritora y bióloga norteamericana Natacha Merritt. Ella nació en San Francisco en 1977; con apenas seis semanas de vida, fue abandonada por su padre. Desde entonces creció con su madre, una francesa liberal. A los dieciocho años conoció a su novio Jerry Preusser, a quien fotografió desnudo y teniendo sexo con ella en varios moteles de Atlanta. Junto a él, viajó a París para estudiar leyes en la Sorbona. Allí descubrió su gusto por la fotografía. Varias sesiones de desnudos con sus amigas modelos le ayudaron a encontrar su vocación de fotógrafa. A su regreso a Nueva York, emprendió la tarea de documentar en fotos su vida sexual (Flores, 2005).

La artista fue descubierta por el fotógrafo y editor norteamericano Eric Kroll, quien encontró sus fotos por casualidad navegando por internet. Para él, las imágenes de Merritt no encajaban en la tradición de las clásicas pin-up o de la fotografía fetichista, género practicado por el propio Kroll.
Según se puede leer en la reseña que figura en Amazon, cualquiera que haya visto Digital Diaries tiene un conocimiento íntimo de la vida sexual de Merritt. Y de sus amigos y conocidos, hombres y mujeres. Sin embargo, el motivo favorito de la autora era ella misma. Ayudada por una cámara digital, la artista se fotografiaba en la cama, en la ducha, teniendo relaciones sexuales con una amiga, masturbándose con y sin accesorios, desde todos los ángulos imaginables $\mathrm{y}$, por lo general, con la cámara a la distancia de un brazo extendido.

Según los editores del libro, las fotografías de Merritt llevan al espectador a reflexionar sobre la sutil diferencia entre lo público y lo privado en la era digital, el narcisismo y la autoexploración del individuo con ayuda de una cámara. Según la reseña: "In her view, she has found a new mode of masturbating her way into the next millennium" (Amazon, s. f.). Maza (2012), por su parte, sostiene que estas imágenes constituyen un viraje en las maneras de representación de la sexualidad femenina en la cultura occidental, dado que esta no es representada, sino que se presenta a partir del propio placer, de la experiencia y del planteamiento de una nueva forma de narrativa por medio de la construcción de lo privado como documento.

El trabajo de Merritt ha sido comparado con el de la fotógrafa norteamericana Cindy Sherman. Veinte años antes, entre 1977 y 1980, ella realizó la serie de fotografías en blanco y negro Untitled Film Stills, considerada una de las más originales e influyentes 
del arte contemporáneo (Sherman, 2009). Inspirándose en el cine de la época, se fotografió usando prótesis en el rostro y en los senos para explorar los diferentes roles de la mujer en la sociedad contemporánea (p. 9).

Década y media después de la publicación de Digital Diaries, Adri Vainilla hizo una exploración erótica similar a la de Sherman y Merritt, esta vez, en plena era digital. En este artículo, analizaremos cómo se construye el capital social en redes sociales a partir del estudio del perfil de Instagram de Adri. Previamente, presentaremos a la artista y definiremos qué es el selfie; luego indagaremos sobre qué es una red social y cómo entender la comunicación en este contexto.

\section{Marco teórico}

\section{Redes sociales}

Siguiendo a Wasserman y Faust (2013, pp. 51-52), definimos una red social como un conjunto o varios conjuntos finitos de actores y la relación o relaciones existentes entre ellos. Según dichos autores, los elementos fundamentales para realizar un análisis de redes sociales son los siguientes:

- El actor. Los actores son unidades sociales discretas individuales, corporativas o colectivas, por ejemplo, personas que forman un grupo, departamentos dentro de una corporación, agencias de servicios públicos de una ciudad o los Estados nacionales del sistema mundial.
- El lazo relacional. Los actores están vinculados entre sí mediante lazos sociales. El rasgo definitorio de un lazo es que establece una vinculación entre un par de actores.

- La díada. En su nivel más básico, es el lazo que se establece entre dos actores mediante un vínculo o una relación entre ellos. Una díada está formada por un par de actores y el (los) posible (posibles) lazo (lazos) entre ellos.

- La tríada. Es un subconjunto de tres actores y el (los) posible (posibles) lazo (lazos) entre ellos.

- El subgrupo. Es cualquier subconjunto de actores y todos los lazos entre ellos.

- El grupo. Es la colección de todos los actores cuyos lazos deben medirse. En este sentido, es un conjunto finito de actores que, por razones empíricas, teóricas o conceptuales, son tratados como tal. Sobre el grupo se hacen mediciones reticulares.

- La relación. Es la colección de lazos de un tipo específico entre los miembros de un grupo. Por ejemplo, el conjunto de amistades entre niños en una clase, o el conjunto de lazos diplomáticos formales entre naciones. Para cualquier grupo de actores, podemos medir varias relaciones diferentes.

- La red social. Es un conjunto o varios conjuntos finitos de actores y la relación o relaciones definidas entre ellos. La información relacional es un rasgo crítico y definitorio de red social. 
Como recuerda Kadushin (2013), si bien la díada es la red social más simple, el análisis de redes comienza en realidad con las tríadas, ya que estas constituyen el inicio de una "sociedad" (p. 49). Hay redes enteras que están formadas por numerosas díadas. Por ejemplo, cada tríada conectada está formada por tres. Otro aspecto fundamental de la red completa es la centralidad o popularidad. Luego está la densidad de la red entera: el número de conexiones o vínculos directos que existen, dividido por el número de posibles vínculos directos. El tamaño siempre es importante. Los grupos pequeños tienden a tener una alta densidad, mientras que las redes grandes, aunque estén conectadas, tienden a tener una intensidad baja (Kadushin, 2013, pp. 53-54).

\section{Capital social}

Bourdieu define el capital social como "la suma de los recursos reales o potenciales que están vinculados a la posesión de una red duradera de relaciones más o menos institucionalizadas de conocimiento o reconocimiento mutuo" (Kadushin, 2013, p. 250). Por su parte, Kadushin (2013) señala que las redes sociales tienen valor porque permiten el acceso a recursos y atributos sociales valorados, como la confianza, la reciprocidad y los valores comunitarios (pp. 235-236).

En este sentido, Van Dijck (2016) sostiene que aquellos individuos con una mayor cantidad de contactos cuentan con más capital social y, por ende, tienden a ser más populares. Por eso, las personas desean mostrarse en los entornos online; tienen un interés creado por construir su identidad compartiendo piezas de información, en la medida en que dar a conocer dicha información acerca de su yo se vincula a la posibilidad de alcanzar cierta popularidad (p. 86).

Esta característica de los entornos online lleva a Sibilia (2008) a afirmar que en el siglo xxI se invita a las personas para que se muestren. De esta manera, lo público y lo privado se confunden. En medio de la globalización de los mercados y en el contexto de una sociedad altamente mediatizada, fascinada por la incitación a la visibilidad y por el imperio de las celebridades, la subjetividad "interiorizada" se desplaza hacia nuevas formas de autoconstrucción. Según recuerda esta autora, algunos ensayistas llaman a este fenómeno sociabilidad líquida o cultura somática de nuestro tiempo. En esta aparece un yo que se exhibe en la superficie de la piel y en las pantallas. Se habla también de personalidades alterdirigidas y no más introdirigidas, construcciones de sí orientadas hacia la mirada ajena o exteriorizadas, no más introspectivas o intimistas. E incluso se analizan las diversas bioidentidades, desdoblamientos de un tipo de subjetividad que se apuntala en los rasgos biológicos o en el aspecto físico de cada individuo (pp. 27-28). Según la autora, ciertos usos de las redes sociales serían estrategias que los sujetos contemporáneos ponen en acción para responder a estas nuevas demandas socioculturales, banalizando nuevas formas de ser y estar en el mundo (p. 28). 
En esta estrategia orientada a mostrarse, la fotografía cumple un papel fundamental. De acuerdo con Sibilia (2008), no es raro que esta termine tragándose al referente para ganar aún más realidad que aquello que en algún momento ocurrió y fue fotografiado. De esta manera, las fotos no solo testimonian, sino que también organizan e incluso conceden realidad a la propia experiencia. Esas narrativas tejen la vida del yo y, de alguna manera, la realizan (p. 40). Este uso de la fotografía se inscribe en la tradición del relato autobiográfico. Citando al crítico literario Philippe Lejeune, Sibilia (2008) señala que las obras autobiográficas se distinguen de las demás porque establecen un "pacto de lectura" que consiste en la creencia de que coinciden las identidades del autor, el narrador y el protagonista de la historia contada (p. 37).

Los usos confesionales de internet parecen encajar en esta definición: el yo que habla y se muestra en la web suele ser al mismo tiempo autor, narrador y personaje. En este sentido, sostiene Sibilia (2008), la experiencia de sí mismo como un yo se debe a la condición de narrador del sujeto. Por lo tanto, usar palabras o imágenes es actuar: gracias a ellas podemos crear universos y con ellas construimos nuestras subjetividades, nutriendo al mundo con un rico acervo de significaciones (p. 38).

\section{Interaccionismo simbólico}

Para analizar este acervo de significaciones, nos encontraremos en la relación entre Adri Vainilla y sus seguidores recurriendo a los postulados del interaccionismo simbólico. El objetivo de esta corriente es estudiar la interpretación por parte de los actores de los símbolos nacidos de sus "actividades interactivas", es decir, la naturaleza simbólica de la vida social. Según nos recuerdan Mattelart y Mattelart (1997), el "interaccionismo simbólico" fue inaugurado por Herbert Blumer en 1937. En 1969, Blumer resumió las tres premisas de esta corriente de la siguiente manera:

1. Los seres humanos actúan respecto de las cosas sobre la base de las significaciones que estas tienen para ellos.

2. La significación de estas cosas deriva de la interacción social que un individuo tiene con los demás actores.

3. Estas significaciones se utilizan con un proceso de interpretación efectuado por la persona en su relación con las cosas que encuentra, y se modifican a través de dicho proceso (Mattelart y Mattelart, 1997, pp. 92-93).

En esta tradición, Erving Goffman combina posteriormente los principios del interaccionismo simbólico con otros enfoques para analizar la retórica de la vida cotidiana. Según él, es necesario que nuestros gestos parezcan verdad como en el teatro (Mattelart y Mattelart, 1997, p. 93). Para este autor, la expresividad del individuo ( $\mathrm{y}$, por lo tanto, su capacidad para producir impresiones) involucra dos tipos de actividad significante (comunicación): 
1. La expresión que da incluye los símbolos verbales o equivalentes que confiesa usar y usa con el único propósito de transmitir la información que él y los otros atribuyen a estos símbolos.

2. Laexpresiónqueemana deél comprende un amplio rango de acciones que los otros pueden tratar como sintomáticas del actor, considerando probablemente que hayan sido realizadas por razones ajenas a la información transmitida en esta forma (Goffman, 2012, p. 16).

Según el mismo autor, el individuo transmite intencionalmente información errónea por medio de ambos tipos de comunicación; el primero involucra engaño, el segundo, fingimiento. En esta línea, si tomamos la comunicación en ambos sentidos, el limitado y el general, descubriremos que, cuando el individuo se encuentra en la inmediata presencia de otros, su actividad tendrá un carácter promisorio; es decir, por lo general, habrá alguna razón para que este se desenvuelva de modo tal que su actividad exprese a los demás la impresión que a él le interesa transmitir. Los demás, por su parte, descubrirán que deben aceptar al individuo de buena fe, ofreciéndole, mientras se encuentre ante ellos, una justa retribución a cambio de algo cuyo verdadero valor no será establecido hasta que él haya abandonado su presencia (Goffman, 2012, p. 17). Siguiendo a Bourdieu, nosotros daremos a este valor la denominación de capital social.

En este punto coincide la forma en que se presenta la persona en las redes sociales con la forma en que esta es percibida por sus pares para construir entre ambos el capital social de los unos y los otros. Este es el punto donde se encuentran los cuerpos de las mujeres con las miradas de los hombres. Para entender este encuentro, emplearemos la perspectiva relacional propuesta por el interaccionismo simbólico, de acuerdo con el estudio realizado por el sociólogo francés Jean-Claude Kaufmann.

\section{Cuerpos de mujeres, miradas de hombres}

En 1995, Kaufmann realizó un estudio sobre la práctica de los senos desnudos en las playas de la Costa Azul francesa. $\mathrm{Su}$ trabajo se inscribe en la corriente del interaccionismo simbólico. Según el sociólogo francés, la escuela interaccionista simbólica demostró la capacidad de la disciplina para dar una dimensión teórica a asuntos de la vida cotidiana (Kaufmann, 2011, p. 235). En este estudio, se desarrollan las siguientes líneas de reflexión:

1. ¿Cuál es el lugar del cuerpo y el de la mirada en nuestra sociedad?

2. ¿Cómo se relacionan hombres y mujeres, y cómo son miradas estas por los primeros?

3. ¿Cuál es la relación entre el individuo y la sociedad?

4. ¿Cuál es el papel de la normativa?

5. ¿Cuál es el papel de la democracia? (pp. 17-19). 
En su investigación, Kaufmann (2011) habla de los roles, analiza el juego de los actores y se refiere abundantemente a la obra de Erving Goffman. Según señala, los materiales estudiados fueron de naturaleza diversa con el fin de descubrir lo que se ocultaba en las cabezas y examinar los gestos en sus mínimos detalles. Para ello, aplicó diversas técnicas:

1. Para descubrir lo que se ocultaba en las cabezas, empleó la entrevista semidirigida.

2. Para analizar los gestos, empleó la observación participante.

En cualquier caso, la observación constituyó un complemento de las entrevistas. Los comentarios recogidos en ellas fueron de una extraordinaria riqueza que permitió, por sus contradicciones, "analizar el proceso de construcción de la identidad, dando pistas (las frases recurrentes) para descubrir los procesos subyacentes" (Kaufmann, 2011, p. 236). Para este autor, la riqueza de los comentarios radica en que cada entrevistado tenía una idea propia, una manera de observar; a cada cual le llamó la atención un elemento que no le interesó a su vecino; cada uno contribuyó con una pieza original, inestimable en la reconstrucción de la verdad (p. 236).

Después de entrevistar a 320 personas, Kaufmann (2011) distinguió tres cuerpos de mujeres, tres miradas del hombre, tres ideas de dominación en pugna, una para mantener su supremacía, la banalidad; las otras dos para intentar imponerse: la sexualidad y la belleza. Desde cada una de las tres perspectivas, el cuerpo de las mujeres era visto en forma diferente (p. 133).

El primer cuerpo de la mujer (la primera mirada del hombre) es el cuerpo banalizado, es decir, el cuerpo que de tanto haber sido visto deja de llamar la atención. Según Kaufmann (2011), este es un cuerpo extraño, una suerte de negación del cuerpo: aquel que se ve sin ver, que no se ve. Esta es la paradoja del proceso de civilización; la exposición de la desnudez hace el desnudo más aparente (p. 135). De acuerdo con los testimonios recogidos por el autor, los senos desnudos son banalizados en la playa, son banalizados en la sociedad en su conjunto, se ven por todas partes. La televisión y la publicidad son señaladas a menudo como instancias supremas de legitimación normativa.

La segunda mirada es la mirada sexual. En la playa, está representada por el mirón, el voyerista avergonzado. Para el sociólogo francés, existe una separación radical entre la mirada que banaliza y la mirada sexual, que no está escrita en ninguna parte. Por un lado, la banalización del desnudo se inscribe en la segunda fase del proceso de civilización. En este contexto, es característica del espacio público, marca la capacidad de dominio de sí mismo lo más cerca del cuerpo y de la sensibilidad. Pero, por otro lado, la liberación sexual funda lo privado mediante un calentamiento de la presencia y del contacto entre los cuerpos, una inmediatez y una intensidad emocional propia del intercambio conyugal (Kaufmann, 2011, p. 142). 
Así, el mismo hombre mira de las dos maneras. En ocasiones miente y disimula para ajustarse a la teoría oficial de la banalización. Numerosas entrevistas recogidas por Kaufmann y su equipo de investigadores son contradictorias; proclaman, en un momento, la realidad de ver sin ver y reconocen, en otro, el placer discreto de una imagen erótica. Según observa el autor, las respuestas son muy diferentes según el contexto. Por ejemplo, son casi opuestas entre mujeres practicantes y no practicantes, entre hombres en pareja y hombres en grupo de hombres. También varían según las preguntas y el sexo del encuestador. Cada situación permite poner en evidencia efectos de deformación, construir una distancia de análisis y, de este modo, acercarse al pensamiento secreto (Kaufmann, 2011, p. 142).

La tercera mirada es la mirada estética. En este caso, según el investigador, el carácter estético de la mirada permite mirar sin parecer un vulgar voyerista. De este modo, la belleza se encuentra puesta en relieve. "Depende de la cualidad estética. Si ellas tienen un seno hermoso, mirar es agradable; si no, no miramos", sostiene uno de los entrevistados (p. 157). Sin embargo, esta mirada no solo se basa en razones estéticas. "Yo, una mujer desnuda, la miro, es una cuestión de admiración", sostiene otro de los entrevistados. Entre el sexo y lo bello, a menudo es difícil distinguir qué es lo que atrae. En este sentido, la mirada estética se sustenta en la sublimación artística de la desnudez (p. 158). Sin embargo, no hay oposición entre la mirada estética y la mirada sexual. "Incluso las jóvenes que son hermosas, que se pueden mirar como una obra de arte, aun así hay un fenómeno sexual", sostiene uno de los entrevistados. "Cuando las formas son hermosas, es erótico", afirma otro informador. De acuerdo con Kaufmann (2011), esta sutil alquimia de la mirada artístico-erótica produce una suerte de confusión lingüística en la que no es extraño que los términos más esteticistas designen los instintos más burdos. Al respecto, una de las mujeres entrevistadas sostiene que, cuando los hombres hablan de belleza, esto se relaciona inmediatamente con la sexualidad (p. 159).

No obstante, el sociólogo francés sostiene que la belleza de la mujer no debe reducirse a sus aspectos superficiales. Siguiendo a Simmel, afirma que la mujer expresa tanto una ética como una estética. Ella es "quien es", mientras que el hombre "llega a ser". Ella nos deja ver "quien es" a través de imágenes exteriores que son, más que nada, signos. Según el autor, pese a que el análisis de Simmel es de principios del siglo $\mathrm{xx}$ y que el movimiento de emancipación de la mujer permitió que ellas también lleguen a ser, la belleza sigue ocupando un lugar privilegiado, hasta el punto de equiparar capital económico masculino contra belleza femenina. Las mujeres siguen siendo "objetos de representación y objetos de un deseo masculino dominante" (Kaufmann, 2011, p. 162). Así, a medida que el hombre carga su mirada de deseo, los senos bellos apuntan hacia lo contrario de lo normal. Se 
convierten en algo que sobrepasa lo corriente, son demasiado bellos para ser invisibles, demasiado bellos para ser banales (p. 168).

Kaufmann (2011) señala que los tres cuerpos de la mujer nunca se separan; cuando uno se muestra, el otro jamás está lejos. La mujer pasa de uno al otro de sus tres cuerpos. Sin embargo, a menudo, no está totalmente en la banalidad ni en la belleza, ni en la sexualidad: está entre dos o entre tres, en una situación equívoca, situada bajo miradas no menos equívocas (p. 169). El autor llama a esta cuarta mirada la mirada ambigua. Protegida por el automatismo y la banalidad, la mujer no tiene conciencia de la ambigüedad; por lo tanto, no se plantea ninguna pregunta, no imagina que pueda ser mirada de forma diferente. Cuanto más segura se siente, más se permite gestos que pueden, sin embargo, dar pie a interpretaciones diversas. Por ejemplo, los hay más clásicos y ejecutados en forma intencional, como las piernas cruzadas bien arriba. También más complejos y extraños, como retocar el maquillaje en público o en lugares falsamente privados (como un vehículo) que están a la vista de todos. En cada caso, el contexto es idéntico, un ritual, un gesto ordinario aparentemente banalizado, que oculta imperfectamente, en la sombra, los otros dos cuerpos de la mujer. Basta con cambiar la mirada para que semejantes escenas se transformen por completo (p. 176).

\section{Objeto de estudio}

Para analizar cómo se construye el capital social en redes sociales, estudiaremos el caso de Adri Vainilla empleando las categorías propuestas por Kaufmann (2011). La presencia de Adri en internet se remonta al año 2004, cuando abrió su ahora desaparecida cuenta en Fotolog. Esto la convierte en la primera mujer peruana que autogestionó su imagen por medios de comunicación virtuales (Cebrián, 2010). Al escribir Adri Vainilla en Google aparecen 110000 resultados. Tiene un blog, una cuenta de YouTube con 1161 seguidores, 33100 seguidores en Instagram, 5754 seguidores en Twitter, 29250 seguidores en su fanpage de Facebook, así como cuentas de Pinterest, Tumblr y SoundCloud.

Adri Vainilla (seudónimo de Adriana Cebrián Vargas) se define a sí misma como "intérprete desconocida, ermitaña exhibicionista, feminista femenina. Amante de la fotografía erótica y pornográfica. Encanto, luego canto" (Cebrián, 2016c). En su desaparecido Fotolog señala que desde niña tuvo inclinación por el arte. Participaba en eventos artísticos de todo tipo en el colegio (Cebrián, 2010). Con respecto a su formación académica, cuenta que, una vez terminado el colegio, su interés por cuestionarlo todo la llevó a estudiar filosofía. Sin embargo, su espíritu explosivo y vital le exigía mucho más (Cebrián, 2010). Por ello decidió cambiar los estudios de filosofía por los 
de comunicación audiovisual, los cuales complementa con clases de teatro. Según ella, en este momento se produce un cambio importante:

El teatro, la improvisación, el escenario, son todos aspectos que repercuten en su alma salvaje, impulsándola a crearse una imagen propia, una figura ficticia, subreal, una que le permita separar su vida privada de su vida artística. Nace así Adri Vainilla. (Cebrián, 2010)

Adri Vainilla frecuentemente ha sido acusada de exhibicionista por sus detractores. Al respecto, ella se pregunta qué tiene de malo subir constantemente fotos de uno mismo a internet (Cebrián, 2013a).

Con respecto a las "feministas" (entre comillas), afirma que le parecen "una sarta de impostoras" (Cebrián, 2013b). Según Adri, ellas aseguran que "yo al sugerir o desnudarme ponía a la mujer como un objeto sexual y que solo lo hacía para hacerme conocida". Sin embargo, se pregunta:

¿Es que no puede una mujer querer disfrutar su sexualidad y ser libre de mostrarse como Dios la trajo al mundo? ¿Es imposible que una mujer se excite y quiera sentirse deseada? ¿Es acaso eso un pecado que debería ser sancionado? (Cebrián, 2013b)

Adri declara que "hablar de sexualidad le divierte muchísimo", de igual manera que hacer fotos semidesnuda o desnuda también, "pero en ningún momento pensé que fuera nocivo para tanta gente. Cuando las personas entendamos el sexo como algo divertido, saludable, placentero y necesario, dejará de haber tanto cinismo, tanto moralista y tanta gente reprimida" (Cebrián, 2013b). Al respecto, sostiene que subir una "foto sexi" a las redes sociales no convierte a una mujer en promiscua o hueca. Desde su punto de vista, compartir una "foto sexi" es una manera de luchar para que los hombres dejen de anular la sexualidad de las mujeres (Cebrián, 2016a).

Adri Vainilla se declara adicta a Instagram. Según $\mathrm{Hu}$, Manikonda y Kambhampati (2014), Instagram es una popular plataforma de captura de fotos $\mathrm{y}$ videos que ofrece a sus usuarios una forma única de publicar estos archivos usando sus teléfonos inteligentes: se pueden aplicar diferentes herramientas de manipulación para transformar la apariencia de una imagen y compartirlas instantáneamente en múltiples plataformas, así como en la página de Instagram del usuario. Además de las funciones de captura y manipulación de fotos, también proporciona conectividad social, lo cual permite a un usuario seguir a otros usuarios, llamados "amigos". Aquellos que siguen a un usuario de Instagram se denominan "seguidores". Se trata de una red social asimétrica, lo que significa que si un usuario A sigue a B, B no necesariamente sigue a A.

Para Adri, Instagram es "una plataforma donde la gente comparte sus fotos, ya sean selfies, fotos con los amigos, fotos de comida y lo peor: fotos de cuando ya acabaron de comer. No hay nada más desagradable que esto último", puntualiza (Cebrián, 2014). Luego concluye: 
Pero nada de eso creo que dañe al ser humano, más bien lo acerca de nuevo a ser sociable, a compartir información, vivencias, gustos y formas de vida, a identificarse entre ellos. El mundo cambia y muchos se agarran de las rejas fuertemente por miedo, cobardía, porque se sienten amenazados o porque simplemente no están preparados mentalmente para vivir el futuro. (Cebrián, 2014)

$\mathrm{Hu}$, Manikonda y Kambhampati (2014) clasifican las fotos compartidas en Instagram en ocho categorías: amigos, comida, gadgets, imágenes subtituladas, mascotas, actividades, selfies y moda. En el caso de Adri Vainilla, predominan los selfies. Con respecto al porqué los millennials se toman decenas de fotos, se ha dicho que los selfies son un ejemplo de cómo las redes sociales nos están haciendo narcisistas. Incluso hay quienes denominan a la búsqueda compulsiva de "me gusta" o shares de otros usuarios el sindrome selfie (Nowsourcing, 2013). Este no es el caso del presente estudio. En esta investigación nos interesará el selfie como moneda de cambio del capital social de las personas.

Un selfie es un tipo de autorretrato fotográfico que, por lo general, se toma con una cámara digital de mano o teléfono con cámara. En el 2013, este término fue incluido en el Oxford Dictionary, que la nombró la palabra del año (Guardian Staff, 2013). Según Mirzoeff (2016), el selfie es la fusión de la imagen de uno mismo, el autorretrato del artista como un héroe y la imagen mecánica del arte moderno que funciona como una representación digital (p. 38). En este sentido, ha creado una nueva manera de pensar en la historia de la cultura visual, como en su momento lo hizo el autorretrato, concluye este autor (p. 39). Para él, el selfie puede ser entendido en dos sentidos. Por un lado, es una nueva modalidad de conversación digital. Por otro, es el primer formato de la nueva mayoría global urbana y juvenil. Y en esto radica su verdadera importancia (p. 63). A pesar de su nombre, el selfie tiene que ver en realidad con los grupos sociales y la comunicación interna de esos grupos. La mayoría de estas fotografías las hacen mujeres jóvenes, por lo general, adolescentes, principalmente para que las vean sus amigos (p. 63).

Esta puesta en escena no es gratuita. Se puede traducir en capital social. Según Van Dijck (2016), los sitios de red social se han convertido en un espacio fundamental para la acumulación de capital social (p. 85). Adri Vainilla es un excelente ejemplo para analizar cómo se materializa el capital social en redes sociales. Pero, si aun así nos sigue preocupando conocer por qué Adri se toma tantas fotos, ella misma confiesa: "Hoy hago fotos para hipnotizar a mis seguidores y lograr, a la vez, que me dejen conocer todos sus secretos. Escribo en mi blog para ver si conmigo aprenden algo, y como también quiero ser sirena, canto para cautivarlos" (Cebrián, 2016b).

\section{Metodología}

Desde el punto de vista metodológico, en este trabajo realizamos un estudio cualitativo en el que combinamos el muestreo 
teórico con la teoría de la hipótesis nula desde la perspectiva del interaccionismo simbólico. Esto quiere decir que enfatizaremos en la naturaleza simbólica de la vida social. De acuerdo con Hernández, Fernández y Baptista (2010), la esencia del enfoque cualitativo de investigación es comprender el punto de vista de los participantes acerca de los fenómenos que los rodean, profundizar en sus experiencias, perspectivas, opiniones y significados, es decir, comprender la forma en que estos perciben subjetivamente su realidad (p. 364).

Una muestra teórica, según Kogan (2010), es un conjunto de sujetos elegidos para la investigación bajo el criterio de que permitirán discutir proposiciones teóricas. El propósito principal del muestreo teórico es la emergencia de teoría y no la verificación de hechos (p. XXVI). El procedimiento fue anticipado por Lindsmith y descrito años más tarde por Glaser y Strauss. El primero lo empleó como una alternativa al muestreo aleatorio. Su intención era probar su teoría sobre el origen de la adicción a las drogas opiáceas tratando de maximizar las oportunidades de que el caso extraño salga a la luz, es decir, intentando averiguar cómo alguien llegaba a ser adicto (Becker, 2011, pp. 117-118). En este sentido, Becker (2010) explica que en el muestreo teórico se parte de "identificar el caso que puede perturbar nuestro pensamiento y buscarlo". Considera que jamás deberíamos suponer que algo es imposible, que simplemente no podría suceder. En cambio, tendríamos que imaginar las posibilidades más alocadas y luego preguntarnos por qué no ocurren (p. 118).

En nuestra investigación, el caso que puede perturbar nuestro pensamiento es el de Adri Vainilla. Estudiar la interacción entre ella y sus seguidores nos permitirá analizar las posibilidades más alocadas para luego preguntarnos por qué no ocurren en otros casos. Para ello, analizaremos una muestra teórica formada por los 104 posts publicados por Adri en su perfil de Instagram en los 30 días comprendidos entre el 30 de agosto y el 28 de septiembre del 2016. A partir de ello, definiremos los conceptos. Según Becker (2010), un concepto es un postulado general sobre clases completas de fenómenos aplicable a personas y organizaciones en todas partes, y no solo a determinadas personas aquí y ahora, o allá y entonces (p. 145). Para analizar cómo se construye el capital social en redes sociales, empezaremos por definir las premisas de las que partimos. La primera de ellas es que todos tenemos una imagen del mundo a partir de la cual actuamos: un imaginario. Por lo tanto, debemos producir la imagen de aquello que estamos estudiando. Con este fin nos apoyaremos en la metodología propuesta por el sociólogo y músico Howard Becker, heredero de la Escuela de Chicago y del interaccionismo simbólico. El campo de observación privilegiado por la Escuela de Chicago es la ciudad como "laboratorio social", con sus signos de desorganización, marginalidad, aculturación, asimilación; la ciudad como lugar de la "movilidad" (Mattelart y Mattelart, 1997, p. 24). 
De acuerdo con Becker (2010), en el estudio de la sociedad comenzamos con imágenes y terminamos con ellas. Por lo tanto, la operación básica es producir y refinar la imagen de aquella cosa que estamos estudiando (p. 29). En este sentido, nuestro imaginario no tiene por qué ser siempre acertado. "Las imágenes desacertadas de las cosas, siempre y cuando sean en algún momento confrontadas con la realidad, pueden ser muy útiles y mostrarnos cómo serían las cosas si fueran del modo que, nosotros lo sabemos muy bien, no son", señala (p. 39).

La clásica versión de este truco del oficio es la llamada hipótesis nula, que afirma una hipótesis que el investigador no considera válida. Para Becker (2010), demostrar que la hipótesis nula es errada equivale a demostrar que otra cosa debe ser correcta, pero sin decir cuál es esa otra cosa (p. 40). En nuestro estudio, la hipótesis nula es que el capital social se construye de manera premeditada. En el camino, las pistas tal vez nos den más datos sobre el observador que sobre el observado.

Para probar esta hipótesis confiamos en lo que suele denominarse estudio de casos; esto es, estudios exhaustivos de situaciones particulares, organizaciones o tipos de acontecimientos. Para realizar esta tarea, es necesario tener en cuenta las siguientes premisas:

1. Considerar y utilizar todo cuanto está presente o vinculado con una situación que se desea comprender.

2. Incluir la idea de cambio o proceso en el análisis, dado que las cosas que estudiamos no ocurren todas al mismo tiempo.

3. Asumir que aquello que se está estudiando en este momento se relaciona con otros elementos fuera del marco construido para el trabajo y que, visto desde otra perspectiva, bien podría ser el centro de ese mismo análisis (Becker, 2016, pp. 17-18).

Como consecuencia de este enfoque, no tendremos generalizaciones atemporales sobre relaciones entre variables. El resultado será la identificación de nuevos elementos en una situación, nuevas cosas que pueden variar en modos que afectarán el resultado que nos interesa, o nuevos pasos en un proceso que creímos comprender hasta que se produjo una consecuencia diferente de la que esperábamos. Podemos usar esos elementos de organización y procesos obtenidos en nuestra siguiente investigación. Según Becker (2016), así funciona la ciencia social. Utiliza el estudio exhaustivo de casos específicos para producir otras preguntas cuyas respuestas, en determinadas situaciones, pueden ayudarnos a comprender qué es lo que ocurre en el mundo social (pp. 18-19).

En esta línea, analizamos el contenido de los comentarios realizados por los seguidores de Adri Vainilla en las diez fotos con mayor engagement de su perfil de Instagram para indagar cómo se construye el capital social en redes sociales (ver anexo). Para Kaushik (2011), el engagement (compromiso) es la tendencia a atraer una atención o un interés favorables, pero, en el contexto de las mediciones o métricas, el reto es 
que este aspecto es muy difícil de medir. En este caso, registramos las siguientes cifras de publicaciones (media), seguidores (followers) y seguidos (following).

Tabla 1. Total de seguidores y seguidos al 28 de septiembre del 2016

\begin{tabular}{llll}
\hline Usuario & Publicaciones & Seguidores & Seguidos \\
\hline adri_vainilla & 3579 & 33811 & 252 \\
\hline
\end{tabular}

Elaboración propia

Adicionalmente, entre el 30 de agosto y el 28 de septiembre del 2016, Adri Vainilla cuenta con un total de 50323 "me gusta" y 1095 comentarios, con un engagement promedio de 1,46.

Tabla 2. Total de "me gusta" y comentarios del 30 de agosto al 28 de septiembre del 2016

\begin{tabular}{ccccc}
\hline Total "Me gusta" (promedio) & Comentarios & $\begin{array}{l}\text { Comentarios } \\
\text { (promedio) }\end{array}$ & $\begin{array}{c}\text { Engagement } \\
\text { (promedio) }\end{array}$ \\
\hline 50323 & 484 & 1095 & 11 & 1,46 \\
\hline
\end{tabular}

Elaboración propia

Sin embargo, ¿cómo honrar en esta tarea a Becker (2016), para quien la realidad es dinámica? Según este autor, el objetivo de la investigación y la teorización sociológicas es definir la índole de todo lo que, de manera observable, contribuye a producir los resultados que le interesan al investigador e incluirlo en su forma de pensarlos (p. 19). Si ponemos el acento en las actividades antes que en las personas, tendremos más interés en el cambio que en la estabilidad, en las ideas de proceso que en la estructura (Becker, 2010, p. 70).
Para representar el cambio, utilizaremos una matriz $2 \times 2$, que es una herramienta visual para la reflexión durante el proceso de síntesis por el que pensamos acerca de las relaciones entre objetos, personas, empresas y productos. Para realizarla, escogemos dos parámetros o características sobre los cuales comparar (uno para cada eje) y, a continuación, dibujamos la matriz 2x2. Los colocamos en el mapa poniendo los extremos de cada parámetro en los de cada eje (Gasca y Zaragozá, 2014, pp. 107-108). 
En esta investigación, en el eje horizontal representaremos, en un extremo, la expresión que emana y, en el otro, la expresión que da el individuo o actuante (en términos de Goffman). En el eje vertical, se encontrarán, en un extremo, el carácter sexual y, en el otro, el carácter no sexual de la mirada del observador (en términos de Kaufmann). Ambos ejes representan los parámetros según los cuales analizaremos cómo se construye el capital social en redes sociales en el caso de Adri Vainilla. Finalmente, usando esta matriz distribuiremos los comentarios recogidos en cada uno de los cuatro cuadrantes según correspondan a las miradas identificadas por Kaufmann.

Figura 1. Matriz 2×2: expresión versus carácter de la mirada

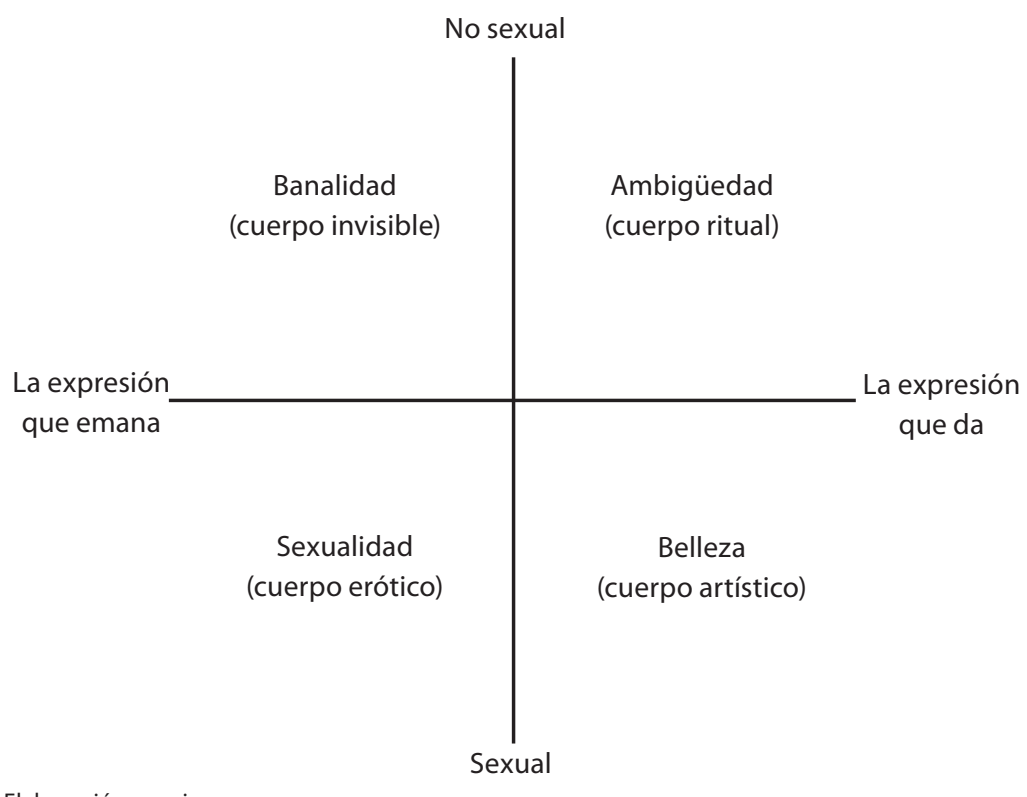

Elaboración propia

\section{Resultados}

En el primer cuadrante, ubicamos la banalidad, que se define como el cruce de la expresión que emana del individuo o actuante y la mirada no sexual del observador. En el caso de Adri
Vainilla, la banalización está representada por aquellos comentarios que invisibilizan su cuerpo. Por ejemplo, en la fotografía de la figura 2, publicada el 27 de septiembre, @tonilegolas comenta: "Buen acabado del piso". En la misma foto, @lpzalb313 escribe: 


\section{Figura 2. Fotografía publicada} el 27 de septiembre

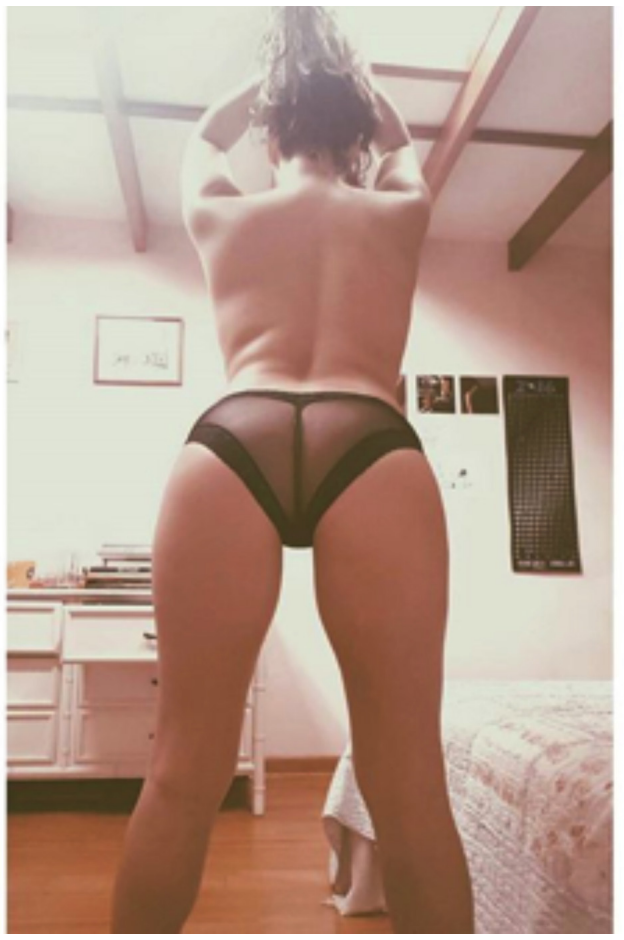

Fuente: Instagram de Adri Vainilla

“Bacán el trabajo en madera del techo @adrivainilla".

En el segundo cuadrante ubicamos la ambigüedad, que es el cruce de la expresión que da el individuo o actuante y la mirada no sexual del observador. En el caso de Adri Vainilla, la ambigüedad no está presente. Según Kaufmann (2011), la ambigüedad implica un comportamiento habitual que oculta los otros dos cuerpos de la mujer: la belleza y la sexualidad. En las fotografías de Adri no hay nada ritual. Ella es consciente de que sus fotos incluyen una dosis de

\section{Figura 3. Fotografía publicada} el 22 de septiembre

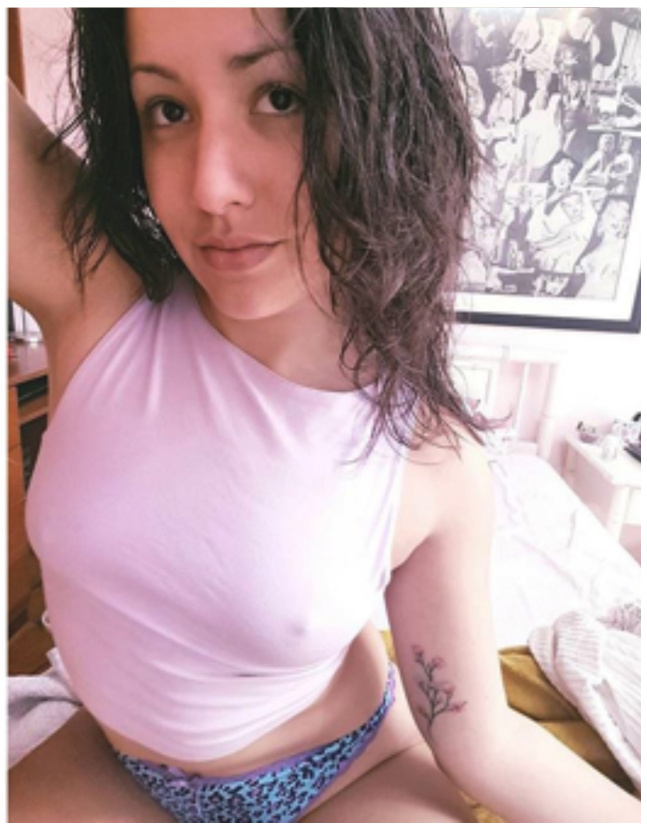

Fuente: Instagram de Adri Vainilla

vanidad, egocentrismo, narcisismo e individualismo.

En el tercer cuadrante, ubicamos la sexualidad, entendida como el cruce de la expresión que emana del individuo o actuante y la mirada sexual del observador. En las imágenes de Adri Vainilla, la sexualidad se enfoca en el cuerpo. Por ejemplo, en la fotografía del 27 de septiembre (figura 2), @yaruzelsky comenta: “Qué rico cuerpo!". En otras ocasiones, la mirada se enfoca en partes corporales específicas. En esta línea, en la foto del 22 de septiembre (figura 3), @sam33e escribe: "Qué pezones pa más ricos bb". Al igual que@ashirdaor420, que dice en 
Figura 4. Fotografía publicada el 31 de agosto

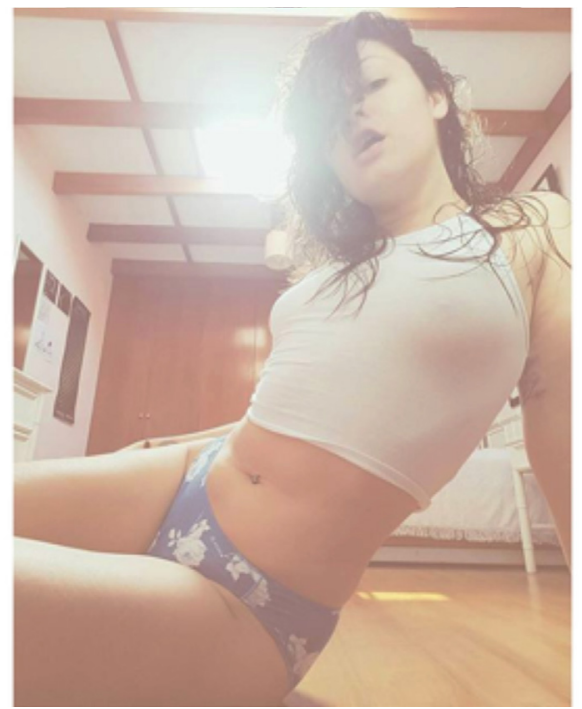

Fuente: Instagram de Adri Vainilla

la misma imagen: "amo tus pezones". $\mathrm{O}$ en la fotografía de la figura 2, @laloshaper menciona: "Good \#nalgas". Otros se animan a hacer peticiones. "Así pero con hilo...", dice @tarazonabr1 en la misma fotografía (figura 2). O expresar deseos: "Las cosas que me gustaría hacer con vos <3", dice @jorge_az17 sobre la foto publicada el 31 de agosto (figura 4).

Finalmente, en el cuarto cuadrante, ubicamos la belleza, a la cual concebimos como el cruce de la expresión que da el individuo o actuante y la mirada sexual del observador. En las imágenes de Adri Vainilla, la mirada basada en la belleza no es la predominante, por lo que es difícil encontrar este tipo de comentarios. Por ejemplo, @diegoarturomarin comenta en la fotografía de la figura 2: "eres mi
Figura 5. Fotografía publicada el 17 de septiembre

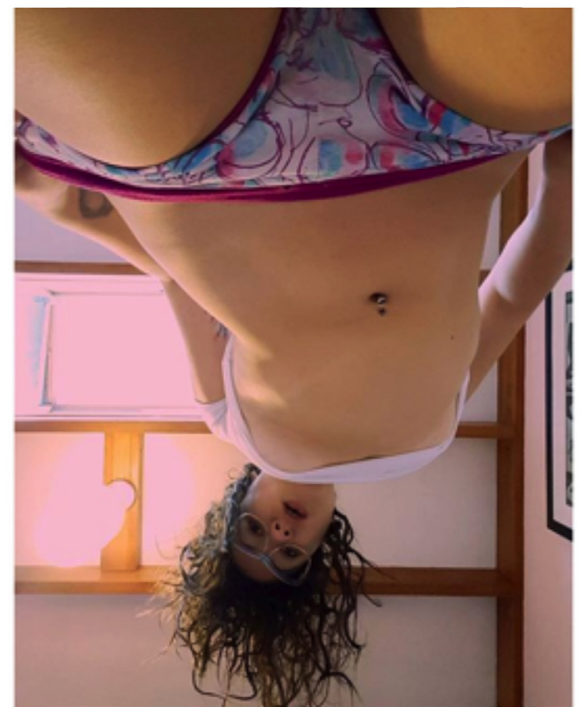

Fuente: Instagram de Adri Vainilla

amor platónico bellaaa!! :*”. Por su parte, @billabong_1974 afirma en la foto publicada el 17 de septiembre (figura 5): “Simplemente BELLA!!!!!". Al igual que @victor_vath, quien escribe en la foto de la figura 3: "Eres sumamente encantadora". Y @luiscuba21 dice en la misma foto: “Eres hermosa y no necesitas posar en prendas diminutas para demostrarlo, la mejor belleza es la de adentro @adri_vainilla".

El análisis de los comentarios de los seguidores del perfil de Instagram de Adri Vainilla muestra el predominio de la mirada sexual. Las palabras que aparecen con mayor frecuencia son hermosa, linda, cuerpo, pezones, guapa, rico, sexi, etcétera. Al igual que en la investigación de Kaufmann (2011), el trabajo 
de examinar los comentarios no permite medir con garantía de absoluta objetividad la importancia de la mirada sexual: solo ha determinado su recurrencia (p. 143). Coincidiendo con lo señalado por Mirzoeff (2016) cuando cita al profesor Ben Agger, esta recurrencia permite afirmar que el selfie es la mirada masculina convertida en viral (p. 64).

La expresión "la mirada masculina" fue acuñada en 1975 por la crítica de cine Laura Mulvey en un estudio sobre el cine clásico de Hollywood para describir una manera dominante de ver. Según ella, el cine construye una mirada que muestra a la mujer como materia prima (pasiva) para la mirada (activa) del hombre.

\section{Figura 6. Fotografía publicada el 12 de septiembre}

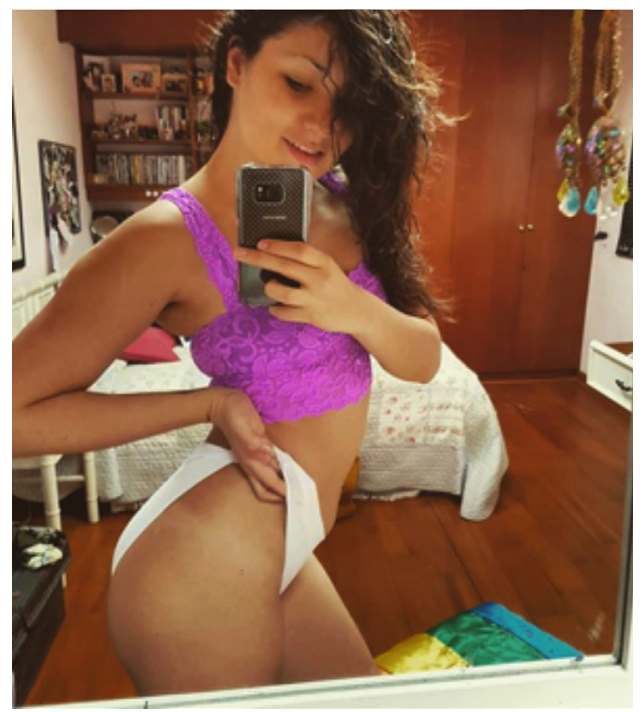

Fuente: Instagram de Adri Vainilla
En el caso de Adri Vainilla, esta mirada masculina se manifiesta en los comentarios de sus seguidores. Algunos parecen conversar con ella. Por ejemplo, @diaz_del96 dice en la foto del 12 de septiembre (figura 6): "Porqueeeeee dime porqueeeee!! $x \mathrm{~d}^{\prime \prime}$. Por su parte, @jackreyes1364 comenta en la misma foto: "Amor déjame ver más estoy rendido a tus pies".

La mirada masculina también se evidencia en el marcado carácter sexual de la mayoría de los comentarios. Por ejemplo, @zreduard dice en la foto de la figura 2: "Me pregunto a quién te cacharás". Por su parte, @jorgeaz17 escribe en la foto de la figura 4: "Las cosas que me gustaría hacer con vos <3". Y @her28wi comenta en la foto publicada el 13 de septiembre (figura 7): "Asu te comería todito esoo".

\section{Figura 7. Fotografía publicada el 13 de septiembre}

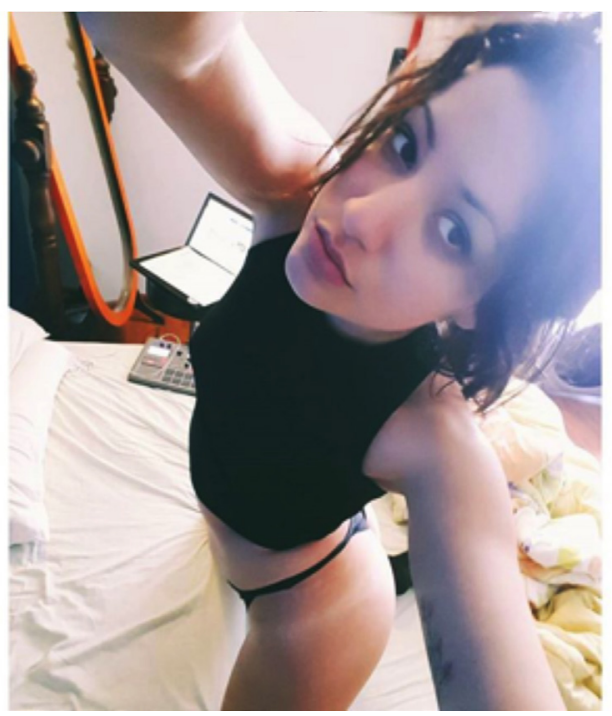

Fuente: Instagram de Adri Vainilla 
Tabla 3. Medidas de tendencia central

\begin{tabular}{lccc}
\hline Medidas & Media & Seguidores & Seguidos \\
\hline Mediana & 49 & 127 & 249 \\
\hline Moda & 0 & 33 & 79 \\
\hline Promedio & 178,36 & 172,22 & 699,76 \\
\hline
\end{tabular}

Elaboración propia

Pero ¿quién es el seguidor de Adri Vainilla? Podemos tener una aproximación si analizamos la relación entre sus publicaciones, sus seguidores y sus seguidos. Para ello, utilizaremos las medidas de tendencia central, que son los puntos en una distribución obtenida, los valores medios o centrales de esta, y nos ayudan a ubicarla dentro de la escala de medición (Hernández, Fernández y Baptista, 2010, p. 292). Las principales medidas de tendencia central son tres:

1. La moda es la categoría o puntuación que ocurre con mayor frecuencia.

2. La mediana es el valor que divide la distribución por la mitad.

3. La media es el promedio aritmético de una distribución (Hernández, Fernández y Baptista, 2010, pp. 292293).

Por ejemplo, en el caso de los sesenta usuarios que comentan la foto de la figura 2, publicada el 27 de septiembre, obtenemos las medidas de tendencia que se muestran en la tabla 3.

Según estos datos, el seguidor promedio de Adri Vainilla registra 178,36 publicaciones, tiene 172,22 seguidores y sigue a un promedio de 699,76 usuarios. Es decir, sigue a cuatro veces más usuarios de los que lo siguen. Una proporción similar se observa en el caso de los usuarios que comentan las otras nueve fotos. También es interesante observar que no es inusual encontrar entre quienes comentan las publicaciones de Adri a usuarios que no han realizado ninguna publicación. Por ejemplo, de los sesenta que comentan la foto de la figura 2, seis no han realizado ninguna publicación durante el tiempo que llevaban activos en Instagram. Es decir, solo comentan o le dan "me gusta" a las publicaciones de otros usuarios.

Según Rudder (2016), todo en internet está plagado de sistemas de valoración o puntuación. Ya sea mediante los votos arriba/debajo de Reddit, las reseñas de los usuarios de Amazon o incluso el botón "Me gusta" de Facebook, las web nos piden que votemos. Ese voto convierte algo que es fluido e idiosincrático (una opinión) en información que los sitios de social media pueden comprender y usar (p. 16). En los casos en que los perfiles de los seguidores de Adri Vainilla son públicos, podemos conocer sus intereses analizando los usuarios a los que siguen. Por ejemplo, @laloshaper 
sigue en su mayoría a figuras públicas nacionales e internacionales como Katy Perry, Kourtney Kardashian, Flavia Laos, Andrea Cifuentes o Spheffany Loza, y deportistas como las surfistas Alana Blanchard, Bethany Hamilton, Melanie Giunta o Analí Gómez.

Finalmente, se identificó una nula o limitada interacción entre los seguidores del perfil de Instagram de Adri Vainilla. Por ejemplo, cuando @rosita_ chg escribe: "eres bonita pero creo k no es dable q cuelgues fotos asííi", @axierpotrero responde: "es su cuerpo puede hacer lo que quiera". Al respecto, cabe señalar que los comentarios provienen en su mayoría de hombres. En el caso de la foto analizada, de los veintiséis comentarios solo uno es de una mujer (el de @rosita_chg).

En resumen, el capital social se construye en la interacción entre la expresión del individuo o actuante y la mirada del observador. Para graficar esta interacción, hemos usado una matriz $2 \times 2$. En uno de los ejes ubicamos las categorías planteadas por Goffman para analizar la presentación de la persona en la vida cotidiana (la expresión que da y la expresión que emana) y en el otro las categorías que caracterizan dicha expresión (en el caso de Adri Vainilla, sexual y no sexual). El análisis reveló la recurrencia de la mirada sexual, es decir, la mirada enfocada en el cuerpo de la mujer.

\section{Discusión}

El 2 de marzo del 2014, durante la entrega del Óscar de ese año, la comediante norteamericana Ellen DeGeneres tomó el selfie más retuiteado hasta ese entonces. En él aparecían actores tan conocidos como Julia Roberts, Brad Pitt, Bradley Cooper, Meryl Streep y Kevin Spacey. Así el selfie dejó de ser una tendencia para convertirse en moda. Hasta entonces, había sido una práctica minoritaria propia de jóvenes (en su mayoría mujeres) que trataban de expresar su identidad. Pero, después de ese día, perdió su significado original para pasar a formar parte del bagaje de la cultura popular.

Sin embargo, ¿en qué se parece una mujer con los senos desnudos en una playa de la Costa Azul a los selfies de una "feminista femenina" en un perfil de Instagram? En que, sin importar los veintiún años que separan 1995 del 2016, en ambos casos se manifiesta el machismo dominante en la sociedad occidental contemporánea. En los dos espacios las mujeres están para ser vistas. En uno, al borde del mar. En el otro, en una publicación en una red social. En ambos, los observadores opinan de ellas refugiados en el anonimato. Como señala Kaufmann (2011), las playas son lugares de gran libertad. En ellas, los individuos se sienten liberados de las restricciones habituales. Pero en las redes sociales, a diferencia del escenario descrito por Kaufmann, los pensamientos se materializan en comentarios públicos. En ellos, los hombres describen, proyectan, imaginan, piden $\mathrm{y}$ ordenan a la mujer en una clara demostración de poder. De allí que Mirzoeff (2016), citando a Anger, afirme que en 
la web el selfie es la mirada masculina convertida en viral. Parece increíble que algo tan banal como un selfie sea la reproducción de estructuras de poder entre hombres y mujeres. Pero así es.

Para entender este fenómeno fue necesario recurrir al análisis relacional y al interaccionismo simbólico. Ambos ponen el énfasis en los actores y en sus acciones como unidades interdependientes. Es a través de estos vínculos que circulan los recursos simbólicos que configuran el capital social de los actuantes.
Y, en el caso de la mujer, el recurso simbólico es el cuerpo. En estos términos, la mujer construye su capital social en redes sociales. Los comentarios recogidos en este estudio así lo demuestran. El capital social en redes sociales de Adri Vainilla no depende de su inteligencia o de su talento como cantante. Depende fundamentalmente de su cuerpo. Su identidad, como la de millones de mujeres en playas, calles, plazas o redes sociales alrededor del mundo, sigue siendo definida por sus cuerpos.

\section{Referencias}

Amazon. (s. f.). Natacha Merritt. Digital Diaries. Recuperado de https://www.amazon. com/Digital-Diaries/dp/B001SARARW

Becker, H. (2010). Trucos del oficio. Cómo conducir su investigación en ciencias sociales. Buenos Aires: Siglo xxI.

Becker, H. (2011). Manual de escritura para científicos sociales. Cómo enseñar y terminar una tesis, un libro o un artículo. Buenos Aires: Siglo xxI.

Becker, H. (2015). Para hablar de la sociedad. La sociología no basta. Buenos Aires: Siglo XXI.

Becker, H. (2016). Mozart, el asesinato y los límites del sentido común. Cómo construir teoría a partir de casos. Buenos Aires: Siglo XxI.

Bowman, D. (6 de mayo del 2000). Digital Diaries. Natacha Merritt's photographs of herself giving head are a high-tech display of sexual narcissism. Recuperado de http://www.salon.com/2000/05/06/digital_4/

Cebrián, A. (2010). Mi biografía. Recuperado de http://www.fotolog.com/iluvadrivainilla/29072457/

Cebrián, A. (2013a). Todo tiempo pasado fue anterior [mensaje en un blog]. Recuperado de http://blogs.larepublica.pe/censurame/2013/10/22/todo-tiempo-pasado-fueanterior/

Cebrián, A. (2013b). Yo me desnudo [mensaje en un blog]. Recuperado de http://blogs. larepublica.pe/censurame/2013/10/08/yo-me-desnudo/ 
Cebrián, A. (2014). Instagram: amenaza latente [mensaje en un blog]. Recuperado de http://blogs.larepublica.pe/censurame/2014/01/24/instagram-amenaza-latente/

Cebrián, A. (2016a). A la vejez, viruela [mensaje en un blog]. Recuperado de http:// blogs.larepublica.pe/censurame/2016/08/15/a-la-vejez-viruela/

Cebrián, A. (2016b). De niña quería ser detective. Soho.

Cebrián, A. (2016c). Feminismo o abuso de poder [mensaje en un blog]. Recuperado de http://blogs.larepublica.pe/censurame/2016/07/26/feminismo-o-abuso-depoder/

Flores, D. (2005). Natacha Merritt: pudor cero. Helio, 26-31.

Gasca, J., y Zaragozá, R. (2014). Designpedia. 80 herramientas para construir tus ideas. Madrid: LID Editorial.

Goffman, E. (2012). La presentación de la persona en la vida cotidiana. Buenos Aires: Amorrortu.

Guardian Staff. (19 de noviembre del 2013). Selfie is Oxford Dictionaries' word of the year. Recuperado de https://www.theguardian.com/books/2013/nov/19/selfieword-of-the-year-oed-olinguito-twerk

Hernández, R., Fernández, C., y Baptista, P. (2010). Metodología de la investigación. México D. F.: McGraw-Hill.

Hu, Y., Manikonda, L., y Kambhampati, S. (2014). What We Instagram: A First Analysis of Instagram Photo Content and User Types. En Proceedings of the Eighth International AAAI Conference on Weblogs and Social Media (pp. 595-598). Recuperado de https://www.aaai.org/ocs/index.php/ICWSM/ICWSM14/paper/ viewFile/8118/8087

Kadushin, C. (2013). Comprender las redes sociales. Teorías, conceptos y hallazgos. Madrid: Centro de Investigaciones Sociológicas.

Kaufmann, J. (2011). Cuerpos de mujeres, miradas de hombres. Sociología de los senos desnudos. Santiago: LOM Ediciones.

Kaushik, A. (2011). Analítica Web 2.0. El arte de analizar resultados y la ciencia de centrarse en el cliente. Barcelona: Gestión 2000.

Kogan, L. (2010). El deseo del cuerpo. Mujeres y hombres en Lima. Lima: Fondo Editorial del Congreso del Perú.

Mattelart, A., y Mattelart, M. (1997). Historia de las teorías de la comunicación. Barcelona: Paidós.

Maza, M. (2012). (Re)presentación de lo privado en la era digital. Digital Diaries de Natacha Merritt. Revista Hysteria. Recuperado de http://hysteria.mx/ representacion-de-lo-privado-en-la-era-digital-digital-diaries-de-natachamerritt/\#prettyPhoto 
Merritt, N. (2015). Natacha Merritt. Recuperado de http://www.natacha-merritt.com/

Mirzoeff, N. (2016). Cómo ver el mundo. Una nueva introducción a la cultura visual. Barcelona: Paidós.

Mulvey, L. (1975). Visual pleasure at Narrative Cinema. Recuperado de https:// www.amherst.edu/system/files/media/1021/Laura\%20Mulvey,\%20Visual\%20 Pleasure.pdf

Napoleoni, L. (2012). 2001-2011. 10 años que conmovieron al mundo. Barcelona: Paidós.

Nowsourcing. (2013). The Selfie Syndrome. How social media is making us narcissistic [infografía]. Recuperado de http://www.bestcomputerscienceschools.net/selfies/

Rudder, C. (2016). Dataclismo. Amor, sexo, raza e identidad; lo que nuestra vida online cuenta de nosotros. Barcelona: Aguilar.

Sherman, C. (2009). The Complete Untitled Film Stills. Nueva York, NY: The Museum of Modern Art.

Sibilia, P. (2008). La intimidad como espectáculo. México D. F.: Fondo de Cultura Económica.

Simmel, G. (2014). Sociología: estudios sobre las formas de socialización. México D.F.: Fondo de Cultura Económica.

Van Dijck, J. (2016). La cultura de la conectividad. Una historia crítica de las redes sociales. Buenos Aires: Siglo xxI.

Wasserman, S., y Faust, K. (2013). Análisis de redes sociales. Métodos y aplicaciones. Madrid: Centro de Investigaciones Sociológicas. 


\section{Anexo}

10 fotos con mayor engagement al 28 de septiembre del 2016, según Seekmetrics ${ }^{1}$

\begin{tabular}{llccc}
\hline Ranking & \multicolumn{1}{c}{ Fotografía } & “Me gusta" & Comentarios & Engagement \\
\hline 1 & 27 de septiembre, 09:30 a. m. & 1336 & 61 & $4.13 \%$ \\
2 & 17 de septiembre, 08:48 a. m. & 1171 & 51 & $3,61 \%$ \\
3 & 31 de agosto, 12:26 a. m. & 1147 & 29 & $3,48 \%$ \\
4 & 22 de septiembre, 11:11 p. m. & 1104 & 27 & $3,35 \%$ \\
5 & 12 de septiembre, 08:55 p. m. & 1088 & 29 & $3,3 \%$ \\
6 & 7 de septiembre, 05:10 p. m. & 977 & 10 & $2,92 \%$ \\
7 & 13 de septiembre, 11:11 a. m. & 977 & 29 & $2,98 \%$ \\
8 & 3 de septiembre, 09:25 a. m. & 905 & 27 & $2,76 \%$ \\
9 & 11 de septiembre, 11:04 p. m. & 893 & 24 & $2,71 \%$ \\
10 & 21 de septiembre, 09:08 a. m. & 879 & 18 & $2,65 \%$ \\
\hline
\end{tabular}

1 Seekmetrics. Recuperado el 28 de septiembre del 2016 de http://seekmetrics.com/insights/adri_ vainilla 
